\title{
INTEGRAÇÃO E ANÁLISE DE DADOS AEROGEOFÍSICOS POR MEIO DA APLICAÇÃO DE TÉCNICAS DE PROCESSAMENTO DIGITAL DE IMAGENS E CLASSIFICAÇÃO NÃO SUPERVISIONADA: O EXEMPLO DO GREENSTONE BELT RIO DAS VELHAS, QUADRILÁTERO FERRÍFERO, MG
}

\author{
Alexandre de Amorim Teixeira ${ }^{1}$, Adalene Moreira Silva ${ }^{2}$, Augusto César Bittencourt Pires ${ }^{3}$, \\ Roberto Alexandre Vitória de Moraes ${ }^{4}$ e Carlos Roberto de Souza Filho ${ }^{5}$ \\ Recebido em 25 agosto, 2006 / Aceito em 17 novembro, 2006 \\ Received on August 25, 2006 / Accepted on November 17, 2006
}

\begin{abstract}
Poor outcrop and deep weathering characterize the Rio das Velhas Greenstone Belt in the southeastern from Brazil. This paper summarizes the use of high-density airborne survey for mineral exploration studies based on interpretation enhancements of magnetic, radiometric and frequency domain electromagnetic data using image-processed methods and an unsupervised classification. The generated products provide new insights and an excellent tool for mapping and trace individual lithological units, improving the information content of the single geophysical channels. The geophysical images were processed using different combinations. The best product was the analytical signal amplitude and inclination integrated by IHS transformation. Information extracted from this image maps the geology and lineament patterns at both regional and local scales. The K-means technique using ten classes was also applied to the geophysical data. These results enhance the lithologies mapped by the field geologists at the 1:100.000. Also shows important host rocks and different gold mineralized geological domains. Such domains host the known gold mineralization, illustrating the utility of these techniques to improve the geological knowledge in the study area.
\end{abstract}

Keywords: Digital Imaging Processing, gold mineralization, Rio das Velhas Greenstone Belt.

RESUMO. Afloramentos escassos e um intemperismo acentuado caracterizam o Greenstone Belt Rio das Velhas no sudeste do Brasil. Este artigo sumariza a utilização de dados aerogeofísicos de alta densidade de amostragem aplicados à exploração mineral baseado no realce e na interpretação de dados magnéticos, radiométricos e eletromagnéticos no domínio da freqüência através de métodos de processamento digital de imagens e classificação não supervionada. Os produtos gerados forneceram novos insights e uma excelente ferramenta para mapeamentos dos diferentes litotipos, melhorando o conteúdo da informação presente nos canais individuais. As imagens geofísicas foram processadas utilizando diferentes combinações. 0 melhor produto obtido foi a integração via IHS da amplitude e da inclinação do sinal analítico. Informações extraídas desta imagem mapeiam tanto a geologia quanto lineamentos na escalas regionais e locais. Aplicou-se a técnica de classificação não supervisionada conhecida com média $\mathrm{K}$ aos dados aerogeofísicos. 0 resultado realça litologias mapeadas por geólogos de campo na escala 1:100.000. Ela mapeia também rochas hospedeiras e diferentes domínios associados com a mineralização aurífera. Tais domínios são conhecidos por hospedar a mineralização aurífera, ilustrando a utilidade destas técnicas para enriquecer o conhecimento geológico da área estudada.

Palavras-chave: Processamento Digital de Imagens, mineralização aurífera, Greenstone Belt Rio das Velhas.

\footnotetext{
${ }^{1}$ Agência Nacional de Águas - ANA, Setor Policial Sul, Área 05 Quadra 03, Bloco "B" - Sala 105, 70610-200 Brasília, DF, Brasil. Tel: +55 (61) $2109-5378$ -E-mail: alexandre.amorim@ana.gov.br

2Laboratório de Geofísica Aplicada, Instituto de Geociências, Universidade de Brasília, 70910-900 Brasília, DF, Brasil. Tel: +55 (61) 3307-2877; Tel./Fax: +55 (61) 3340-4759-E-mail: adalene@unb.br

${ }^{3}$ Laboratório de Geofísica Aplicada, Instituto de Geociências, Universidade de Brasília, 70910-900 Brasília, DF, Brasil. Tel: +55 (61) 3307-2877; Tel./Fax: +55 (61) 3340-4759-E-mail: acbpires@unb.br

${ }^{4}$ HGeo/InterGeo, SCLN 111, Bloco C, Salas 219/221, 70754-530 Brasília, DF, Brasil. Tel./Fax: +55 (61) 32744533 - E-mail: rmoraes@hgeointergeo.com.br

${ }^{5}$ Instituto de Geociências (IG), Universidade Estadual de Campinas (UNICAMP), Caixa Postal 6152, 13083-970 Campinas, SP, Brasil. Tel: +55 (19) 3788-4535; Fax: +55 (19) 3289-1097 - E-mail: beto@ige.unicamp.br
} 


\section{INTRODUÇÃo}

No que tange à integração de dados multifontes para mapeamento geológico, não existe uma técnica que contemple a complexidade dos diversos tipos de rochas e suas alterações intempéricas ou hidrotermais. Assim, esforços têm sido despendidos no intuito de gerar novas metodologias e procedimentos que auxiliem na definição de domínios definidos nestes dados e que se correlacionem espacialmente e espectralmente com a unidade litológica, esteja ela alterada ou não.

A região do Quadrilátero Ferrífero permite esse tipo de pesquisa, devido ao grande acervo de dados de geologia básica, aerogeofísica e de prospecção geoquímica, gerados por órgãos governamentais e empresas de mineração. 0 greenstone belt Rio das Velhas hospeda alguns dos mais importantes depósitos auríferos do país, bem como apresenta uma grande diversidade litológica caracterizada por rochas vulcânicas e metassedimentares, com expressivas zonas de alteração hidrotermal.

Produtos integrados por meio de Processamento Digital de Imagens e Classificadores Hierárquicos permitem a geração de temas que possibilitam uma nova compreensão do caráter estrutural e litológico da região. No entanto, ainda é necessário refinar, desenvolver, aplicar e comparar novas técnicas neste sentido. 0 foco deste trabalho é auxiliar a interpretação geológica e a compreensão das mineralizações auríferas no greenstone belt Rio das Velhas. No que tange a uma continuação no processamento de dados aerogeofísicos já desenvolvido (Silva, 1999), a deconvolução de Euler representa uma tentativa de se compreender 0 comportamento espacial das fontes magnéticas relevantes e sua relação com arcabouço estrutural e mineralizações associadas. Dentro desta ótica será apresentada uma discussão sobre os métodos utilizados, visando apresentar as vantagens e desvantagens de cada produto integrado no processo de interpretação estrutural e litológica para o ambiente estudado.

\section{CONTEXTO GEOLÓGICO}

0 Quadrilátero Ferrífero (QF) situa-se na borda sul do Cráton São Francisco e representa uma parte preservada de um antigo núcleo maior denominado de Cráton do Paramirim (Almeida, 1977). Devido ao seu potencial mineral o QF é alvo de estudos geológicos sistemáticos desde o final do século XIX.

Os litotipos aflorantes abrangem uma área de aproximadamente 7190 km² e são constituídos de terrenos granitos-gnáissicos; Greenstone Belt Arqueano; seqüências supracrustais do Paleoproterozóico e do Mesoproterozóico (Chemale Jr et al., 1991 e 1994) (Figura 1).
Os terrenos granito-gnáissicos do QF e de suas imediações apresentam, às vezes, uma forma dômica e compreendem diversos complexos: Caeté, Bonfim, Belo Horizonte e Santa Rita. São polideformados e os contatos com as unidades supracrustais adjacentes são de natureza tectônica. Esses complexos metamórficos são constituídos, majoritariamente, por ortognaisses do tipo TTG, migmatizados ou não. Apresentam intrusões de granitóides, anfibolitos e pegmatitos. As rochas dos complexos foram geradas preferencialmente nos ciclos Arqueano e Transamazônico (Cordani et al., 1980 e 1989; Teixeira, 1985; Machado et al., 1989; Romano, 1989; Machado \& Carneiro 1992; Carneiro et al., 1995; Noce, 1995; Noce et al., 1992; Teixeira et al., 1996).

As rochas do Greenstone Belt Arqueano (Schorscher 1978) são agrupadas no Supergrupo Rio das Velhas (SGRV), dividido nos Grupos Nova Lima e Maquiné. Ladeira (1980) propôs dividir 0 Grupo Nova Lima em três unidades, da base para 0 topo: unidade metavulcânica, unidade metassedimentar química, unidade metassedimentar clástica. Segundo Schrank \& Silva (1993), parte importante do pacote sedimentar é representado por seqüências turbidíticas de composição básica a félsica. Sobreposto a esse conjunto encontra-se 0 Grupo Maquiné que foi dividido em duas formações, da base para o topo: Palmital e Casa Forte (Dorr, 1969).

Não existe uma subdivisão válida para o SGRV como um todo. Pinto \& Silva (1996), Zuchetti et al. (1996) propuseram uma nova subdivisão estratigráfica para o Greenstone Belt Rio das Velhas. Pinto \& Silva (1996) propõem elevar as unidades a categoria de formações. Segundo Zuchetti et al. (1996) estas unidades foram definidas por observações de campo, com 0 apoio de estudos petrológicos e geoquímicos. Um empilhamento estratigráfico clássico das unidades não foi efetuado devido à alta magnitude de deformação, 0 elevado grau de intemperismo e extensão da bacia de deposição. Ainda, de acordo com Pinto \& Silva (1996), as unidades foram agrupadas em blocos tectônicos, denominados de: Nova Lima, Caeté, Santa Bárbara e São Bartolomeu, que segundo os autores, retratam ambientes petrogenéticos distintos (Figura 2).

Dentro dessas modificações foi mantida a designação formal de SGRV, com os Grupos Nova Lima (base) e Maquiné (topo). No entanto, o Complexo Córrego dos Boiadeiros e o Grupo Quebra Osso foram redefinidos como formações e englobados dentro do Grupo Nova Lima. 0 Complexo Córrego dos Boiadeiros foi separado como um sill ultrabásico intrusivo na base do Grupo Nova Lima (Zucchetti et al., 1996; Pinto \& Silva, 1996).

0 Supergrupo Minas (SGM) sobrepõe-se aos dos TTG's e SGRV, geralmente em contato tectônico. Este divide-se em três 


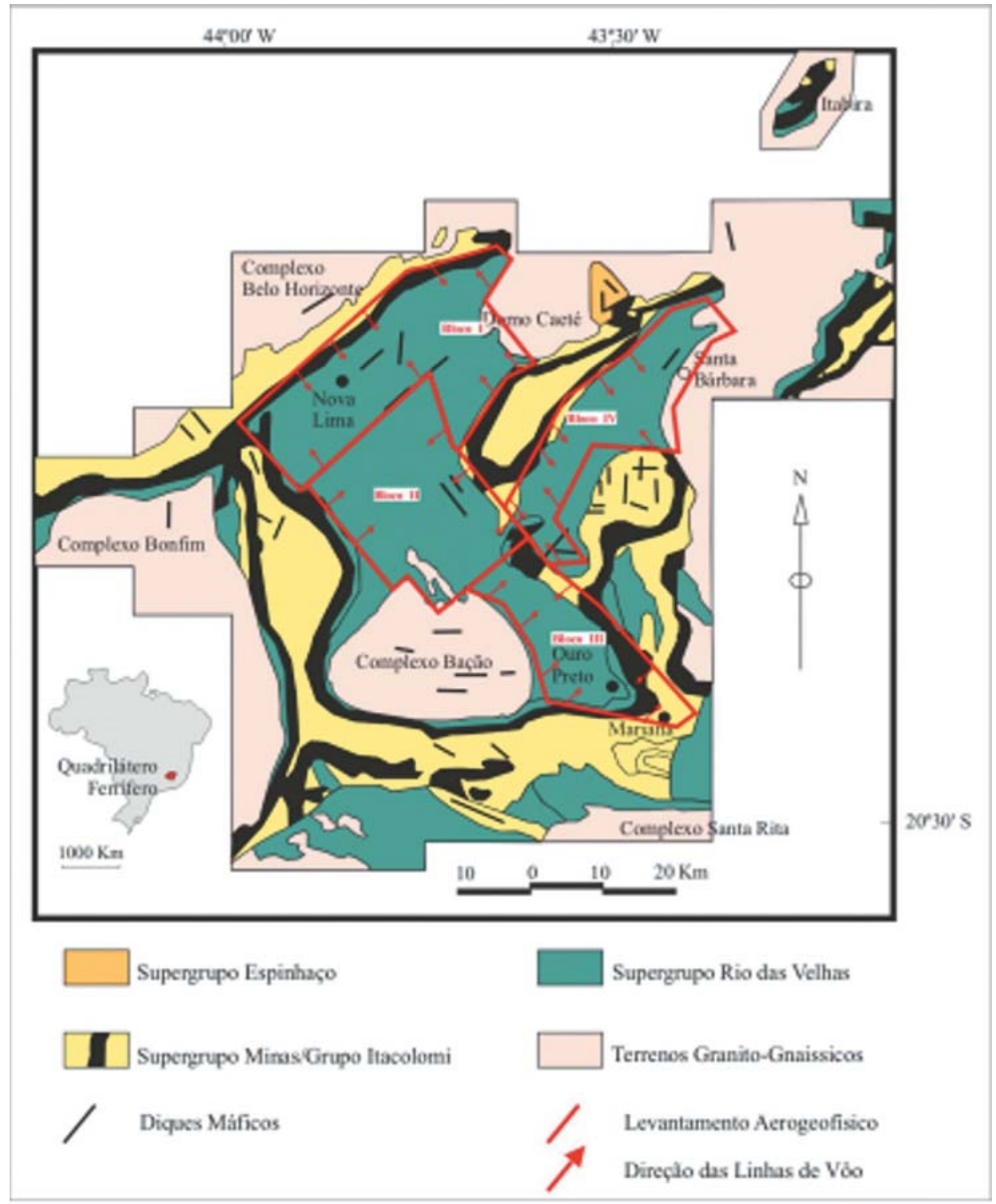

Figura 1 - Mapa Geológico do Quadrilátero Ferrífero, MG (Modificado de Dorr, 1969 in Silva, 1999).

grupos, da base para o topo: Caraça, Itabira e Piracicaba (Dorr, 1969; Cordani et al., 1980 e 1989; Ladeira \& Viveiros, 1984; Alkmim \& Marshak, 1998; Carneiro et al., 1995; Noce, 1995).

0 Grupo Caraça apresenta, na base, a Formação Moeda, constituída por quartzitos com intercalações de filitos e níveis conglomeráticos auríferos-uraníferos na porção basal. Esta transiciona para a Formação Batatal, onde predominam filitos sericíticos, por vezes carbonosos ou ferruginosos.

0 Grupo Itabira inicia pela Formação Cauê, composta por formações ferríferas bandadas do tipo Lago Superior e, subordinadamente, por filitos ferruginosos e dolomitos. A Formação
Gandarela, no topo do grupo, exibe mármores dolomíticos, subordinadamente, itabiritos e filitos.

A unidade basal do Grupo Piracicaba, Formação Cercadinho, caracteriza-se pela alternância de quartzitos e filitos, freqüentemente ferruginosos. A Formação Fecho do Funil é constituída por filitos quartzosos, filitos dolomíticos e lentes de dolomito. As Formações Taboões (ortoquartzitos) e Barreiras (filitos grafitosos) são de ocorrência restrita.

A unidade superior do Grupo Piracicaba, Formação Sabará, é constituída por clorita xistos, filitos, metagrauvacas, metatufos, metaconglomerados, quartzitos e formação ferrífera subordinada. 

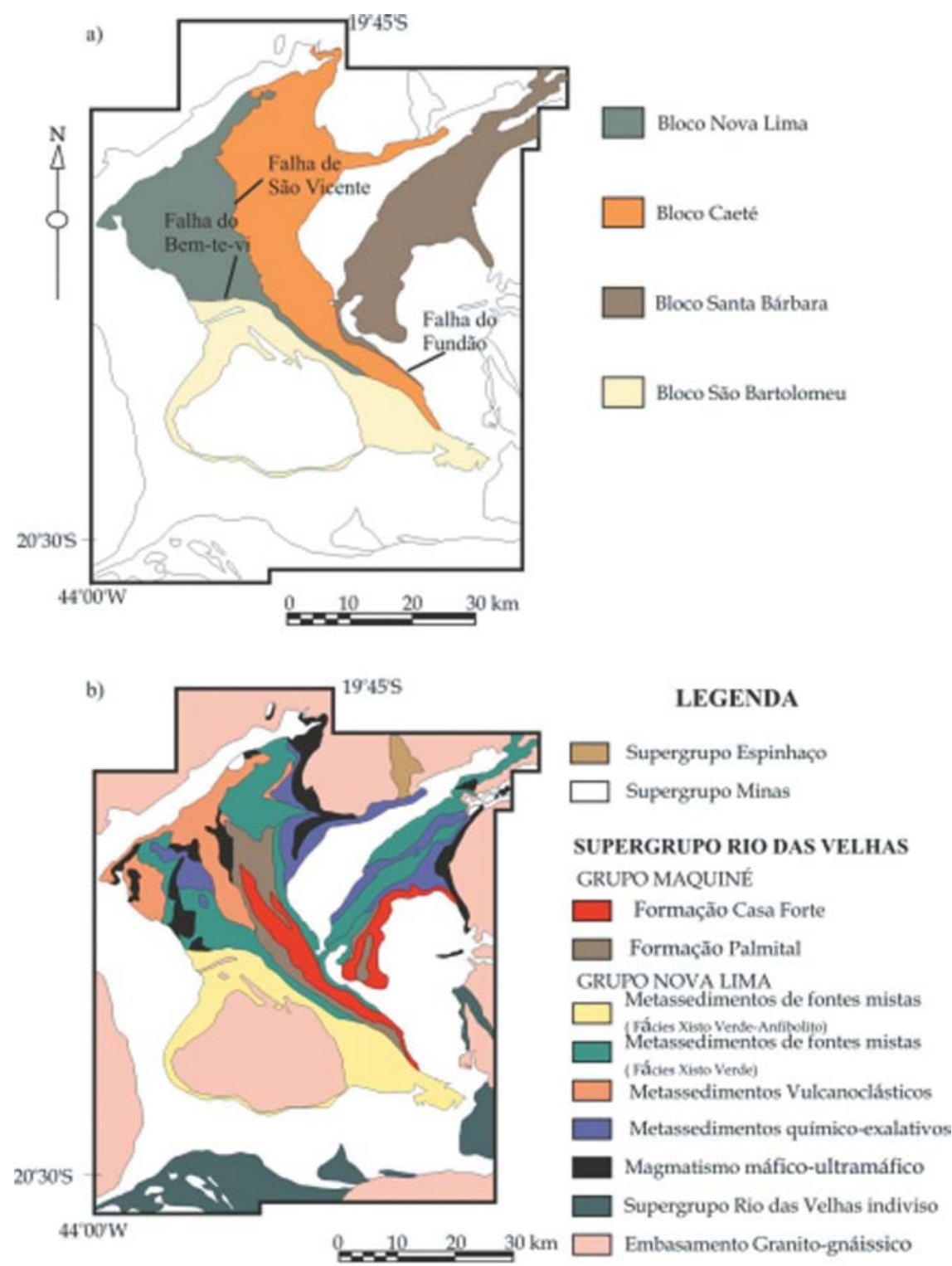

Figura 2 - Nova subdivisão estratigráfica para o Greenstone Belt Rio das Velhas. As unidades foram agrupadas em blocos tectônicos, denominados de: Nova Lima, Caeté, Santa Bárbara e São Bartolomeu, que segundo Pinto \& Silva (1996), Zuchetti et al. (1996) retratam ambientes petrogenéticos distintos.

Segundo Dorr (1969), a Formação Sabará possui uma espessura máxima de $3000 \mathrm{~m}$, aproximando-se da espessura máxima atingida pelo conjunto das demais unidades do SGM, que é de 3500 m. Barbosa (1968) e Ladeira (1980) propõem a elevação da Formação Sabará à categoria de grupo, devido a sua espessura e presença de litotipos diferenciados. Segundo Reis et al. (2002), 0 Grupo Sabará representa uma bacia de antepaís compartimentada, gerada durante a deformação, soerguimento e erosão dos depósitos Arqueanos e Paleoproterozóicos do Cinturão Mineiro.
0 Supergrupo Espinhaço é representado por um pacote rochas quartzíticas a nordeste do Quadrilátero Ferrífero, na Serra das Cambotas. A posição estratigráfica desta unidade foi sempre controvertida por incluir pacotes distintos de rochas, tectonicamente justapostos (Freitas et al., 1991; Crocco-Rodrigues et al., 1991).

Dentro do quadro geológico regional do Quadrilátero Ferrífero, deve-se destacar também a existência de uma densidade razoável de corpos ígneos máficos intrudindo as unidades Arque- 
anas a Fanerozóicas. Duas gerações de diques máficos de direção predominantemente NS cortam os terrenos granito-gnáissicos (TTG) do QF e regiões adjacentes (Carneiro, 1992). São encontrados também sil/s e diques de rochas básicas de direção NS, ora deformados, ora metamorfizados, com idades em torno de 1,7 G.a (Carneiro et al., 1995; Silva et al., 1995). A intrusão de diques máficos na região do QF foi mais expressiva durante a abertura do protooceano Brasiliano/Panafricano (Silva et al., 1995). 0 último evento, de idade Mesocenozóica aflora na forma de diques de direções variáveis, não apresentando deformação nem metamorfismo. A origem destes diques está relacionada à fragmentação do Supercontinente Gondwana (Silva et al., 1995).

As rochas dos terrenos granito-gnáissicos foram metamorfizadas em condições de fácies anfibolito a granulito (Hertz, 1978) e retrometamorfizadas em xisto verde, enquanto que as supracrustais do SGRV e do SGM evidenciam paragênese metamórfica de fácies xisto verde a anfibolito (Hertz, 1978; Hoefs et al., 1982; Ladeira, 1980; Marshak \& Alkmim, 1989). Localmente, as condições metamórficas do SGM atingem apenas 0 anquimetamorfismo. Hertz (1978) e Jordt-Evangelista et al. (1991) descrevem auréolas de metamorfismo de contato em torno Complexo Bação e na porção norte da Serra do Curral, respectivamente.

\section{DADOS AEROGEOFÍSICOS}

0 projeto Rio das Velhas consiste de aerolevantamento geofísico sistemático utilizando os métodos magnetométrico, gamaespectrométrico e eletromagnetométrico (domínio da freqüência) (incluindo VLF) de alta densidade, com o objetivo de identificar novos alvos auríferos em zonas de Greenstone belt (Hildenbrand \& Perez da Gama, 1993).

A escolha desses métodos teve por base a boa resposta geofísica esperada para as rochas do Greenstone belt Rio das Velhas que apresentam contraste de susceptibilidade magnética com as rochas máfico-ultramáficas/formações ferríferas e zonas de cisalhamento. Já a gamaespectrometria, contribui com a diversidade litológica causada pela variação de concentração dos radioelementos K, U e Th, e sua relação com eventos hidrotermais. 0 método eletromagnético indica a presença de corpos condutores como sulfetos maciços e filitos carbonosos.

0 aerolevantamento foi realizado em 1992 e as linhas de vôo foram orientadas perpendicularmente à direção preferencial das rochas do Supergrupo Rio das Velhas no interior da área (Figura 1) com espaçamento das linhas de vôo de 250, amarrados por linhas de controle de 5000 metros. Os sensores foram mantidos a uma altura de 60 metros, por sobre a topo- grafia, para 0 gamaespectrômetro de 45 metros para 0 magnetômetro/VLF e de 30 metros para 0 eletromagnetômetro. A taxa média de amostragem do eletromagnetômetro é de \pm 5 metros (5 leituras/segundo), a do magnetômetro é de \pm 5 metros (5 leituras/segundo), a do VLF - EM é de \pm 5 metros (5 leituras/segundo) e, finalmente, o gamaespectrômetro possui taxa de amostragem de \pm 25 metros (1 leitura/segundo). A velocidade de operação do helicóptero utilizado como plataforma esteve entre 70 a $110 \mathrm{~km} / \mathrm{h}$. 0 eletromagnetômetro empregou três bobinas coplanares com transmissores centrados nas freqüências de 500 , 4.175 e $33.000 \mathrm{~Hz}$ e duas bobinas coaxiais com 935 e $4600 \mathrm{~Hz}$. 0 afastamento (transmissor/receptor) foi de 7 metros.

Os dados aerogeofísicos utilizados nesse trabalho foram processados por Silva (1999) e reprocessados por Fuck (2001). 0 processamento destes dados envolveu a edição e junção dos quatro blocos representativos da amostragem feita numa base de dados única.

Após esta etapa, os dados foram interpolados. Para os dados magnetométricos e eletromagnetométricos (resistividade aparente), 0 método de interpolação mais eficiente foi 0 bidirecional (implementado no Oasis Montaj como bi-grid), com célula quadrada de 50 metros de lado. No caso dos dados gamaespectrométricos utilizou-se o método da curvatura mínima (Fuck, 2001). Os métodos de interpolação foram testados exaustivamente e, posteriormente, analisados não só através da análise visual, mas também através do espectro de potência. A seguir, as diferentes malhas interpoladas foram micronivelados com 0 emprego de algoritmo otimizado (Fuck, 2001), o qual tratou especificamente os problemas de desnivelamentos encontrados nas diferentes áreas abrangidas pelo aerolevantamento.

\section{Magnetometria}

A análise do relevo referente ao campo magnético anômalo foi auxiliada por suas transformações lineares. A amplitude do sinal analítico foi usada na demarcação da posição horizontal das fontes magnéticas. A fase do sinal analítico possui um padrão textural que auxilia a caracterização dos domínios magnéticos e feições lineares. A utilização das derivadas, principalmente das verticais, ajudou na compreensão das posições espaciais relativas destas fontes e as horizontais, ajudaram na demarcação em mapa.

A Figura 3 apresenta-se um dos mapas com as soluções da equação de Euler gerados neste trabalho que apresentou a menor dispersão (índice estrutural $\mathrm{N}=1$, Linha de pólos - tipo dique semi-infinito), feito na tentativa de se compreender 0 comportamento dos falhamentos. Seguindo a proposta de Reid et 


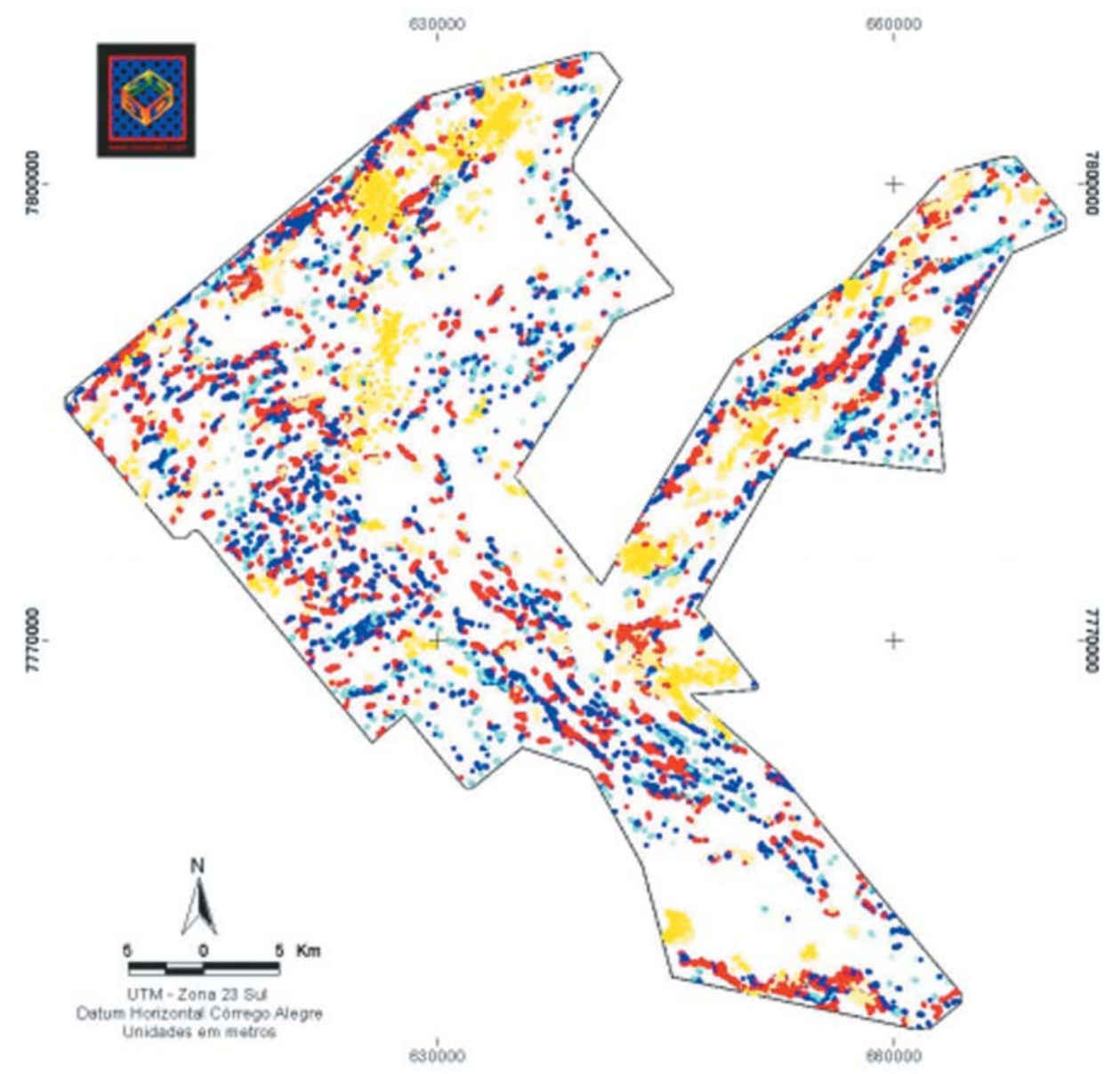

Figura 3 - Mapa de estimativa de profundidade de fontes magnéticas por deconvolução de Euler. Legenda: Muito Raso, Raso (ciano claro), Pouco Raso (ciano escuro), Pouco Profundo (azul), Profundo (vermelho), Médio Profundo (amarelo claro), Muito Profundo (amarelo escuro).

al. (1990), utilizaram-se janela de $10 \times 10$ células da malha do campo magnético anômalo com dimensões espaciais de 50, 125, 250 e 500 metros. Essa ação visa a determinação de corpos em maiores profundidades à medida que se aumenta o tamanho da janela. Para tanto, também se calculou a profundidade dos corpos com tolerâncias de 5,10 e $15 \%$ para todas as malhas. Quanto maior esta e menor é 0 tamanho da célula da malha, maior é 0 número de ocorrências calculadas. Desse modo, a escolha da tolerância visou limitar a grande quantidade de ocorrências geradas pelas células menores e ampliar o número das ocorrências calculadas pelas células maiores. Foram escolhidas as tolerâncias de 5\% para malhas com células de 50 e 125 metros; de 10\% para aquelas com células de 250 metros e, por fim, 15\% para as de 500 metros. Todas as estimativas feitas foram corrigidas para a superfície do terreno.

As estimativas de profundidades foram classificadas em se- te classes ( $\mu \pm n \sigma ; n=-3,-2,-1,0,1,2,3$ ) usandose distribuição log-normal (Tabela 1), visto que visualmente 0 gráfico de freqüência das estimativas de profundidade apresenta esse tipo de distribuição.

Tabela 1 - Reclassificação das estimativas de profundidade.

\begin{tabular}{|c|c|}
\hline $\begin{array}{c}\text { Intervalo da } \\
\text { profundidade estimada } \\
\text { (metros) }\end{array}$ & Classificação \\
\hline $0-62$ & Muito Raso \\
\hline $62-119$ & Raso \\
\hline $119-230$ & Pouco Raso \\
\hline $230-436$ & Pouco Profundo \\
\hline $436-852$ & Profundo \\
\hline $852-1643$ & Médio Profundo \\
\hline $1643-3706$ & Muito Profundo \\
\hline
\end{tabular}




\section{Gamaespectrometria}

0 procedimento utilizado na interpretação dos dados gamaespectrométricos envolveu: a) a comparação da imagem correspondente a cada canal discriminado (K, U, e Th) com a topografia para estudar a influência do relevo sobre estes dados; b) a análise do canal de contagem total para a definição de grandes domínios gamaespectrométricos, bem como a análise da contribuição relativa de cada um dos outros canais; c) o uso de composições em falsa cor (imagem ternária) do tipo RBG e CMY, com os canais de $\mathrm{K}$, Th e $\mathrm{U}$, usando ou não o modelo digital de terreno como uma quarta componente e seu estudo espacial para definir unidades e/ou domínios com assinaturas gamaespectrométricas semelhantes; d) uso das razões $\mathrm{U} / \mathrm{Th}$, Th/K e U/K na análise da sua correlação com os diversos domínios gamaespectrométricos e com as regiões onde estão mapeadas as mineralizações na região.

\section{Eletromagnetometria}

As imagens com a resistividade aparente foram geradas a partir dos valores interpretados existentes. Vale ressaltar que estas imagens podem não só apontar corpos condutores importantes para exploração mineral, mas podem ser uma boa ferramenta para mapeamento geológico. Os dados com os resultados das resistividades calculadas para as freqüências de 935, 4175 e $33000 \mathrm{~Hz}$ foram interpolados utilizando o método bi-direcional com célula de 50 metros e a seguir, micronivelados semelhantemente à magnetometria. Depois, foram convertidos para condutividade (Silva, 1999).

Na verdade, as assinaturas identificáveis nas imagens com os resultados da resistividade, podem ser detalhadas pelas da condutividade e vice-versa. As imagens de condutividade mostraram pequenas variações nesta propriedade nos litotipos do Greenstone Belt Rio das Velhas, o que parece ser típico de terrenos Pré-cambrianos (Palacky, 1991). As imagens com os logaritmos destes valores detalharam melhor estas assinaturas, visto que em rochas pré-cambrianas as diferenças entre os valores de condutividade são muito pequenas (Palacky, 1991; Silva, 1999). De acordo com Palacky (1991), as freqüências eletromagnéticas baixas e médias constituem canais melhores para mapear condutores múltiplos e pequenos alvos em profundidade, devido a problemas associados a ruídos. Em terrenos tropicais, como aqueles do presente trabalho, 0 canal médio mostra uma imagem com menor quantidade de ruído. 0 canal de $33.000 \mathrm{~Hz}$ mostra forte contribuição antrópica, apesar da alta razão sinal/ruído (Silva, 1999). Uma das questões chaves versa sobre a profundidade das fontes. A quantificação depende de muitos fatores como a freqüência utilizada e a resistividade do meio (Silva, 1999). Cálculos baseados em Zonge \& Hughes (1991) mostram uma profundidade estimada de 20 metros para o canal de $33.000 \mathrm{~Hz}$, 50 metros para 0 canal médio $(4175 \mathrm{~Hz})$ e de 100 metros para 0 canal de $935 \mathrm{~Hz}$.

0 canal de $4175 \mathrm{~Hz}$ revelou ser 0 melhor produto, pois apresenta alta razão sinal/ruído (Silva, 1999) e foi, portanto, 0 único a ser utilizado na integração de dados. A profundidade de observação foi calculada e estimada em torno de 50 metros.

\section{PROCESSAMENTO DIGITAL DE IMAGENS AEROGEOFÍSICAS (PDI)}

Neste trabalho utilizaram-se as seguintes técnicas de PDI: Composição Colorida RGB, IHS e Principais Componentes.

\section{Composição colorida RGB}

As composições coloridas falsa-cor no espaço RGB utilizadas para realçar e combinar os dados aerogeofísicos são: RGB (K, Th e U) e RGB (Amplitude do Sinal Analítico, Condutividade-canal de $4.175 \mathrm{~Hz}$ e Canal de Contagem Total) (Figura 4).

Na Figura 4, as áreas vermelhas representam regiões com alta susceptibilidade magnética, baixa condutividade e baixos valores de radiação gama. Já as áreas amarelas representam áreas com alta susceptibilidade magnética e alta condutividade, mas com baixa radiação.

\section{Sistema IHS}

Utilizou-se, também, a transformação IHS para integrar as informações aerogeofísicas desse trabalho. Assim, fundiu-se a fase do sinal analítico e a primeira derivada vertical do campo magnético anômalo com as imagens de amplitude do sinal analítico, condutividade $(4.175 \mathrm{~Hz})$ e composição colorida falsa-cor RGB (K, Th e U) (ex. Figura 5). Os melhores resultados são aqueles provenientes da integração dos dados eletromagnéticos e amplitude do sinal analítico, pois realçam domínios magnéticos e condutivos que são sabidamente conhecidos por hospedar mineralizações auríferas em BIFs fácies óxido na região.

\section{Principais componentes}

Aplicou-se a análise por principais componentes aos dados gamaespectrométricos ( $K, T h, U)$, juntamente com a amplitude do sinal analítico e o canal de condutividade de $4.175 \mathrm{~Hz}$, utilizando a matriz de covariância. A Tabela 2 apresenta os autovetores gerados por principais componentes e a Tabela 3 apresenta a matriz de correlação entre as variáveis geofísicas. 


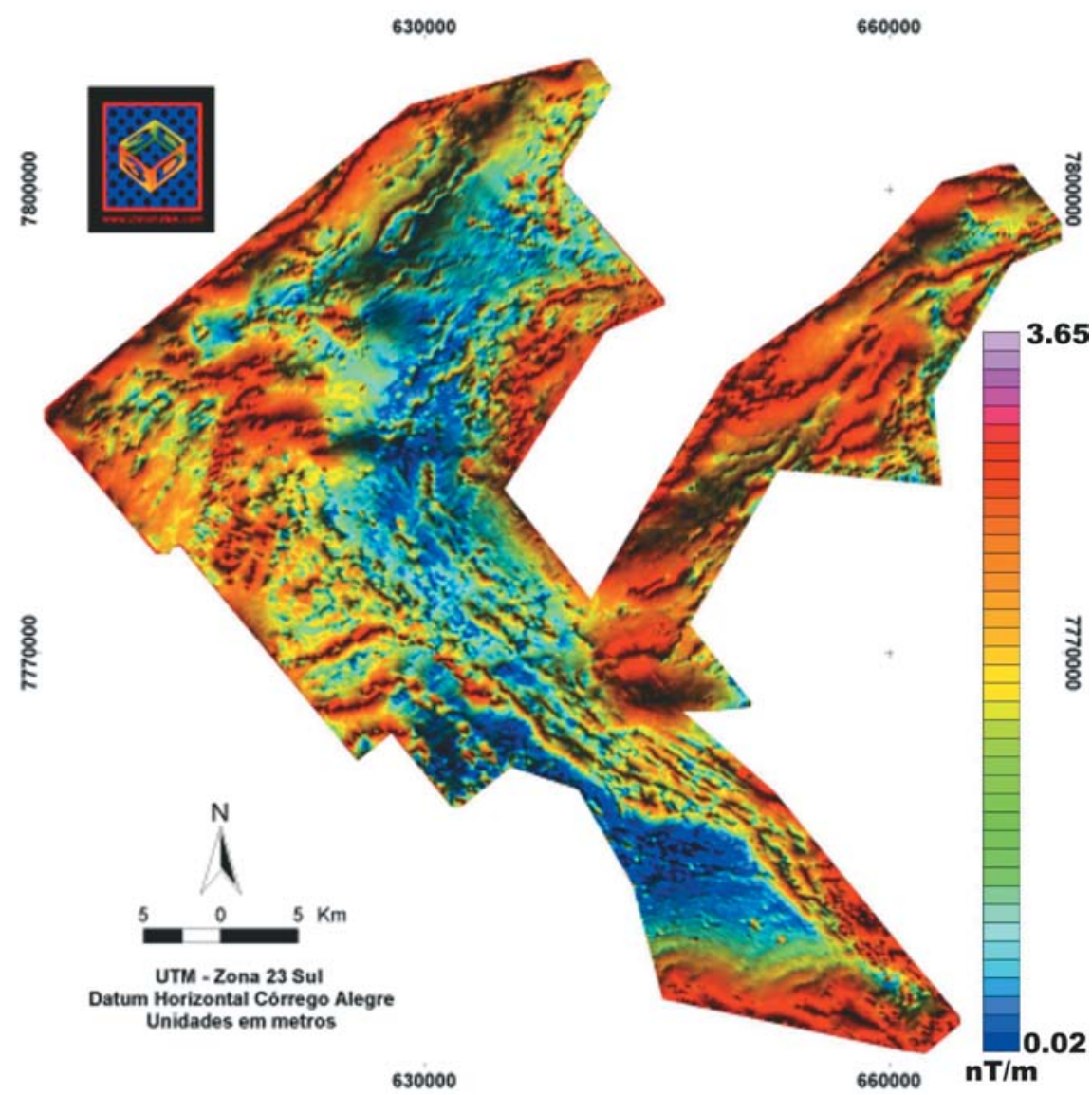

Figura 4 - Imagem da fusão da Amplitude do Sinal Analítico e Fase do sinal analííco (intensidade).

Tabela 2 - Tabela de autovetores da transformada por principais componentes.

\begin{tabular}{|c|c|c|c|c|c|c|}
\hline & $\mathrm{K}$ & Th & $\mathrm{U}$ & ASA & $\mathrm{C}(4.175 \mathrm{~Hz})$ & Autovalores $(\%)$ \\
\hline PC1 & $-0,64$ & $-0,37$ & $-0,17$ & $+0,47$ & $+0,427$ & 37,70 \\
\hline PC2 & $+0,03$ & $+0,36$ & $+0,19$ & $+0,79$ & $-0,432$ & 23,90 \\
\hline PC3 & $-0,56$ & $-0,21$ & $-0,04$ & $-0,27$ & $-0,752$ & 18,65 \\
\hline PC4 & $+0,51$ & $-0,74$ & $-0,23$ & $+0,24$ & $-0,245$ & 14,40 \\
\hline PC5 & $-0,02$ & $-0,34$ & $+0,93$ & $-0,03$ & $+0,07$ & 5,3 \\
\hline
\end{tabular}

Tabela 3 - Matriz de correlação das variáveis geofísicas.

\begin{tabular}{|c|c|c|c|c|c|}
\hline & $\mathrm{K}$ & Th & U & ASA & C(4.175Hz) \\
\hline $\mathbf{K}$ & 1 & 0,28 & 0,21 & $-0,24$ & $-0,19$ \\
\hline Th & 0,28 & 1 & 0,44 & $-0,05$ & $-0,21$ \\
\hline $\mathbf{U}$ & 0,21 & 0,44 & 1 & $-0,006$ & $-0,22$ \\
\hline ASA & $-0,24$ & $-0,05$ & $-0,006$ & 1 & 0,09 \\
\hline $\mathbf{C ( 4 . 1 7 5} \mathbf{~ H z})$ & $-0,19$ & $-0,21$ & $-0,22$ & 0,09 & 1 \\
\hline
\end{tabular}




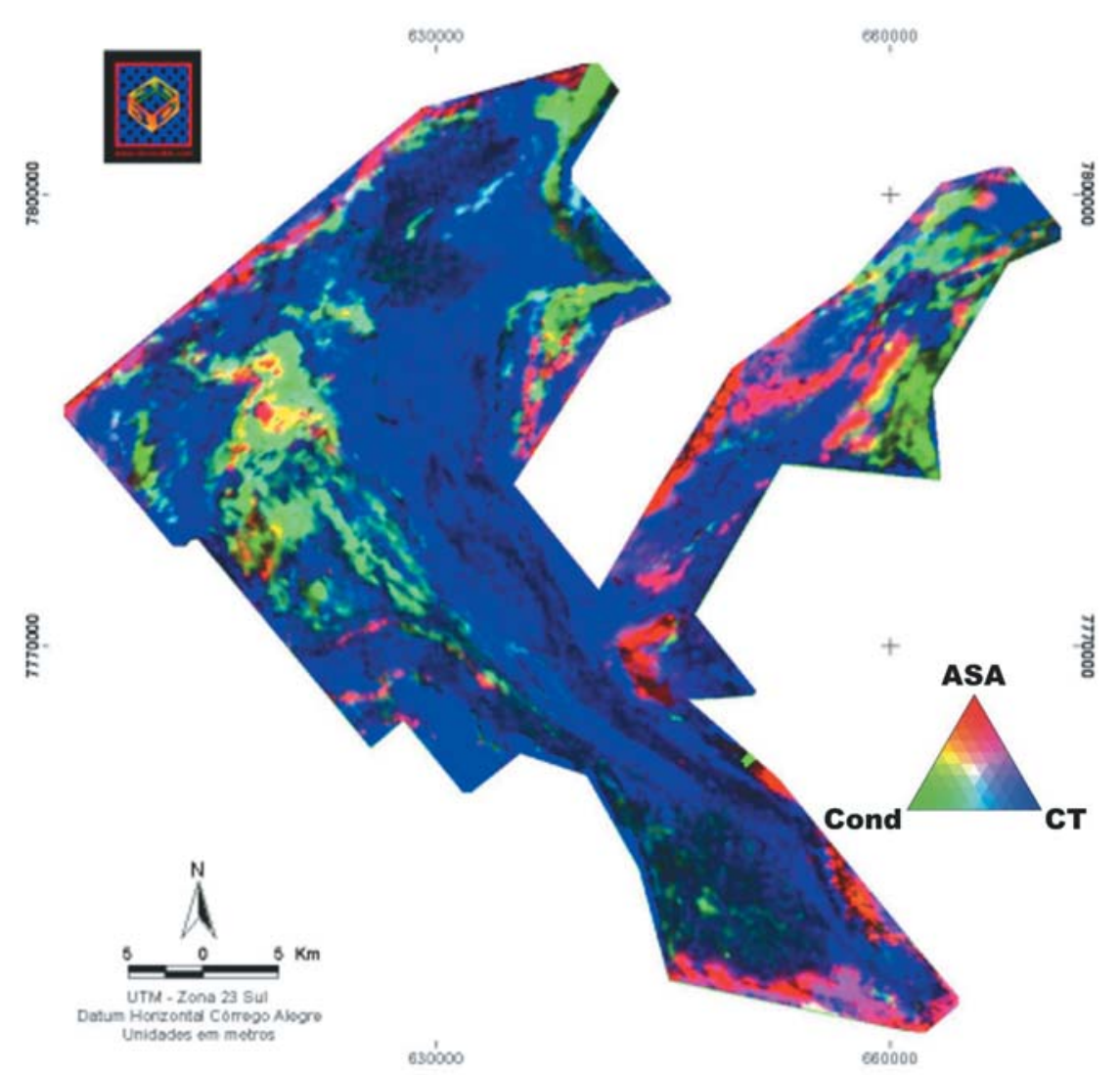

Figura 5 - Composição colorida falsa-cor RGB (Amplitude do sinal Analítico, Condutividade no canal 4.175Hz e Canal de Contagem Total).

Observa-se pela tabela de autovetores (Tabela 2) que, de uma forma geral, os canais gamaespectrométricos apresentam peso semelhante ao longo de todas as principais componentes. Isso ocorre principalmente por causa da afinidade geofísica desses elementos em comparação com as propriedades físicas dos outros planos de informação, como susceptibilidade magnética e condutividade e pode ser comprovado pelos valores observados na matriz de correlação (Tabela 3).

A melhor composição de imagem utilizando as principais componentes compreende a composição colorida falsa-cor RGB, para realce litológico, com a PC1 no vermelho, a PC4 no Verde e a PC2 no Azul (Figura 6). Observa-se pela tabela de autovetores (Tabela 2) que a PC1 possui maior peso da amplitude do sinal analítico e da condutividade $(+0,47 \mathrm{e}+0,42$, respectivamente), em contrapartida, a contribuição dos canais gamaespectrométricos é negativa. Esses domínios são estratégicos para exploração mineral na região do Grupo Nova Lima. Já a PC4 possui peso positivo para o canal de potássio e para a amplitude do sinal analítico, realçando assim, domínios magnéticos com possível alteração hidrotermal. Por fim, a PC2 possui contribuição positiva de to- dos os canais com exceção do canal condutivo. A escolha dessa componente no canal azul é para homogeneizar a composição dos planos de informação na imagem colorida. Essa composição colorida, com apenas três bandas, sintetiza $76 \%$ da variância total das informações gamaespectrométricas, magnetométrica e condutiva.

\section{CLASSIFICAÇÃO NÃO SUPERVISIONADA VIA MÉDIA K}

A maioria das técnicas hierárquicas pode necessitar da criação e manipulação matrizes de similaridade extremamente grandes se o número de amostras for elevado, o que é comum nos dados produzidos pelas técnicas de geofísica aérea. Por isso, foram concebidos procedimentos de agrupamento usando um número limitado de centros arbitrários de grupos visando reduzir a dificuldade computacional. Sem dúvida, um dos mais usados dentre estes é o procedimento da média-K (K-means). Nesta técnica, $k$ pontos caracterizados por $m$ variáveis são designados como centróides iniciais dos grupos. Uma matriz de similaridades entre os $k$ centróides e as $n$ amostras é calculada e as amostras mais similares são agrupadas ao centróide mais próximo. №- 


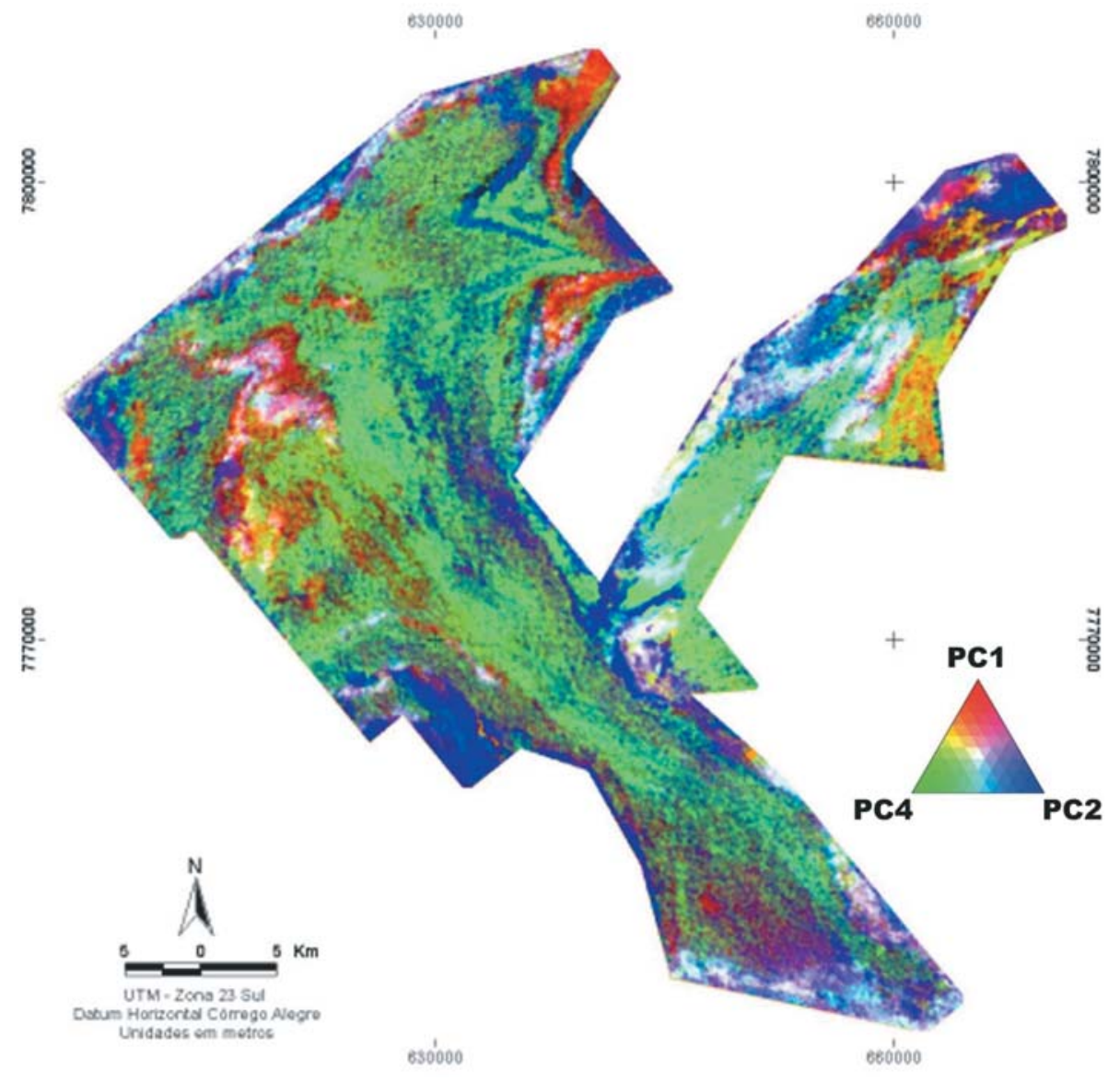

Figura 6 - Composição colorida falsa-cor RGB (PC1, PC4 e PC2).

vos centróides são então calculados e o processo segue interativamente até todas as amostras haverem sido classificadas. Em princípio, o centróide se deslocará rapidamente em direção ao centro verdadeiro de um grupo em crescimento, na medida em que informações verdadeiras sobre este se sobrepuserem àquela inicialmente arbitrária.

Neste artigo foram testadas diversas combinações de informações visando definir o que melhor caracterizasse os diferentes litotipos da região estudada, e conseqüentemente, as rochas hospedeiras da mineralização aurífera. Os dados foram exaustivamente testados para diferentes classes e diferentes interações. As classificações estatísticas efetuadas mostraram que os dados possuem em média dez classes. Portanto, foi efetuado um grupamento em dez classes, após dez interações utilizando as seguintes informações: canais de potássio, tório, urânio, bem como a amplitude do sinal analítico e o canal de condutividade $(4.175 \mathrm{~Hz})$. Todos os dados foram reescalonados para 8 bits, ou 256 tons de cinza (Figura 7).
A Figura 8 mostra a assinatura geofísica das classes resultantes da classificação não supervisionada por média-k. Todos os planos de informação, bem como todas as classes pertencentes aos mesmos, foram reclassificados em relação à sua média em baixo, baixo-médio, médio, médio-alto e alto.

\section{DISCUSSÕES E CONCLUSÕES}

0 melhor produto resultante da transformação IHS para interpretação estrutural é a amplitude do sinal analítico com a fase do sinal analítico no canal de intensidade (Figura 5). Assim, ao mesmo tempo em que se identifica a posição da fonte magnética, pode-se identificar uma assinatura do mergulho do gradiente da anomalia. Observa-se que a Zona de Cisalhamento São Vicente varia o mergulho de falha ao longo da sua extensão, o que é validado pelos trabalhos anteriores na área (Araújo, 2001). As áreas mineralizadas ao longo da falha apresentam assinatura padrão com valores de fase do sinal analítico próximo a zero. As estimativas de profundidade das fontes magnéticas por meio da 


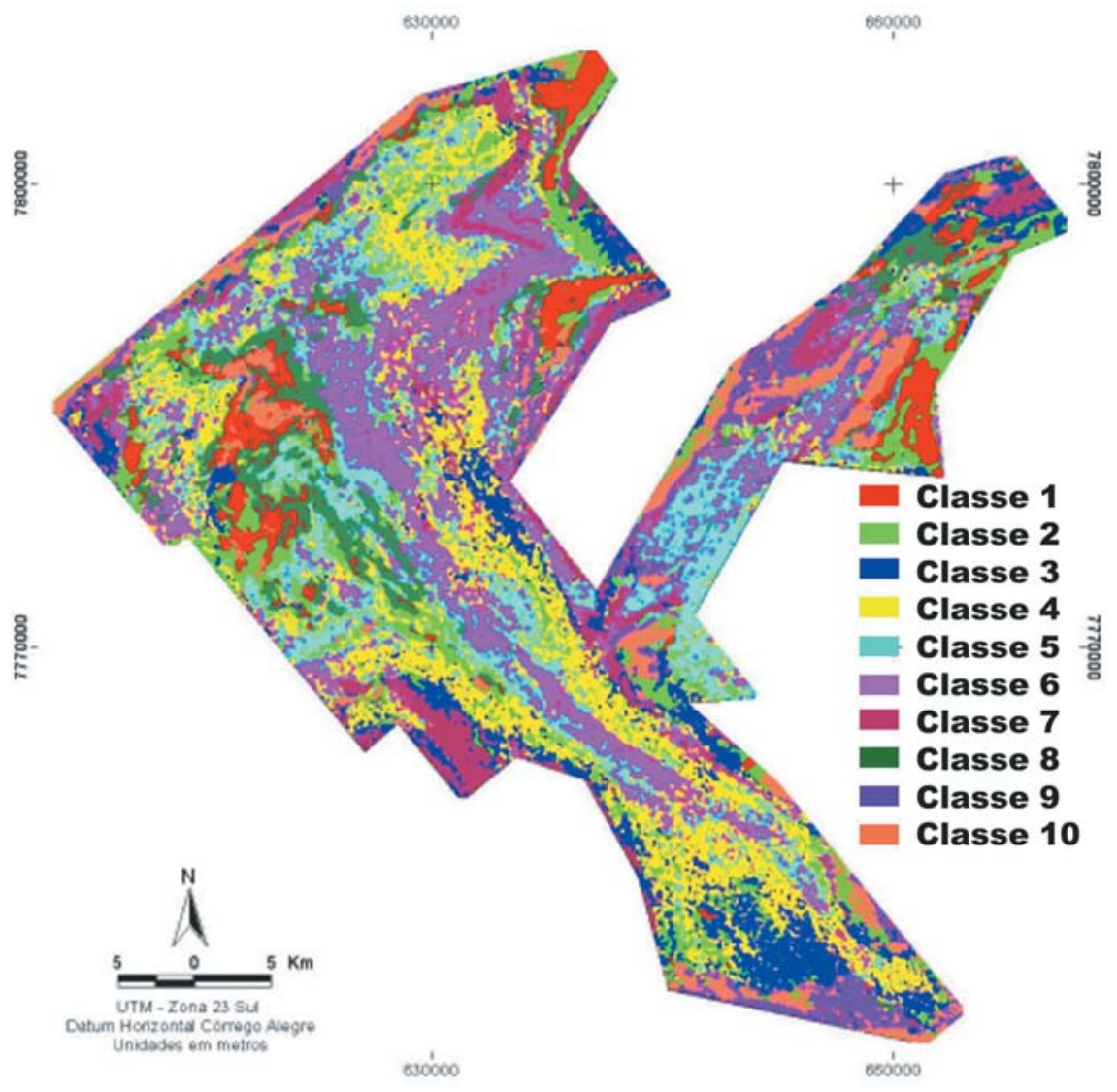

Figura 7 - Classes resultantes da aplicação da técnica de classificação não supervisionada por média-k. Legenda: Classe 1: vermelho, Classe 2: verde claro, Classe 3: azul marinho, Classe 4: amarelo, Classe 5: ciano, Classe 6: magenta, Classe 7: marrom escuro, Classe 8: verde escuro, Classe 9: roxo e Classe 10: marrom claro.

deconvolução de Euler auxiliam 0 entendimento do comportamento geométrico dessa falha em profundidade. No geral, a faIha apresenta pouca profundidade (200 $\mathrm{m}$ a $400 \mathrm{~m}$ ) com algumas áreas profundas ( $400 \mathrm{~m}$ a $800 \mathrm{~m}$ ). A análise qualitativa da fusão Fase/Amplitude do sinal analítico (Figura 5) e da deconvolução de Euler (Figura 3) permite a determinação de zonas homólogas a partir da textura da fase do sinal analítico, dos valores de amplitude do sinal analítico e dos lineamentos das estimativas de profundidade da deconvolução de Euler.

A partir das classes obtidas pela classificação por média-k dos dados aerogeofísicos, pôde-se associar a assinatura de algumas classes (Figuras 7 e 8) com unidades litoestatigráficas do Supergrupo Rio das Velhas mapeadas no projeto Rio das Velhas (Pinto, 1996) na escala 1:100.000. Assim, os BIFs, de uma forma geral, se correlacionam com a classe 10 , caracterizada principalmente por baixos valores de radiação e alta amplitude do sinal analítico. A Formação Quebra-Osso, composta por magmas ultramáficos com textura spinifex e sills cumuláticos, correlaciona com a classe 1 e apresenta baixos valores radiométricos e alta condutividade. Localmente, correlaciona-se a classe $2 \mathrm{com}$ essa formação onde ela é mais magnética, porém, não condutiva. A Formação Morro Vermelho caracteriza a classe 8 e diferencia-se da classe 1 por possuir médios valores de radiação, porém, muito condutiva. Essa formação caracteriza-se por pequenas lentes de sedimentos químicos exalativos como BIFs do tipo algoma, metacherts e xistos carbonáticos. A classe 7 correlaciona-se com a Formação Ribeirão Vermelho composta por rochas metassedimentares vulcanoclásticas e constituem-se de tufos dacíticos piroclásticos e aglomerados de baixo fluxo. Essa classe caracterizase por altos valores de radiação de $\mathrm{K}$, Th e $\mathrm{U}$ e por médio a baixos valores magnéticos e condutivos. A Formação Córrego do Sítio representa as rochas metassedimentares de fontes mistas do Grupo Nova Lima (Pinto \& Silva, 1996) e caracteriza-se por finas intercalações de quartzo-sericita-clorita xisto e feldspato-quartzo 


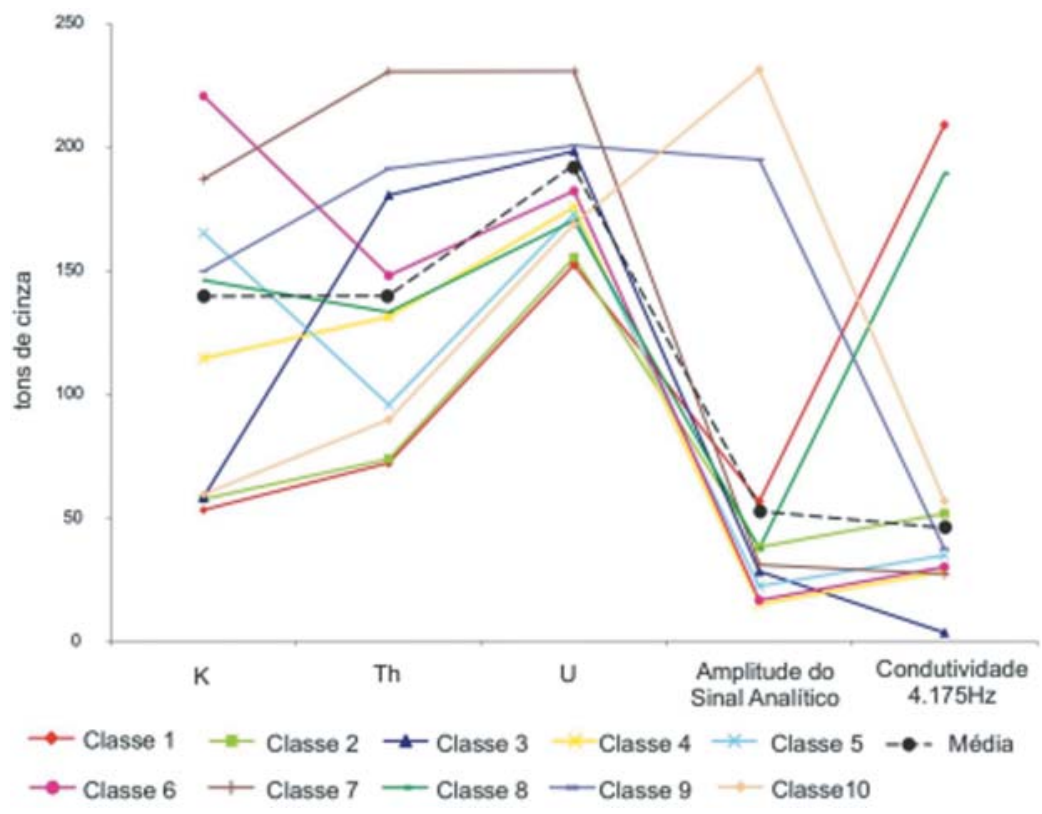

Figura 8 - Assinatura Geofísica das classes resultantes da classificação não supervisionada por média-k.

xisto interpretados como metapelitos e metagrauvacas com finas intercalações de xistos carbonáticos e BIFs. Essa unidade correlaciona-se com as classes 4 e 5 . Na parte norte há uma predominância da classe 4 que possui assinatura com médios a médio-baixos valores dos dados geofísicos. Porém, na região ao longo da Zona de cisalhamento São Vicente que apresenta mineralizações do tipo load, há a predominância da classe 5 , que reflete, provavelmente, a alteração hidrotermal da classe 4 caracterizada pelo alto valor relativo de K e baixo valor de Tório. Podese correlacionar a classe 5 com a PC4 da Análise por Principais Componentes dos dados aerogeofísicos descrita anteriormente.

\section{REFERÊNCIAS}

ALKMIM FF \& MARSHAK S. 1998. Transamazonian Orogeny in the Southern São Francisco Craton Region, Minas Gerais, Brazil: evidence for Paleoproterozoic collision and collapse in the Quadrilátero Ferrífero. Precambrian Research, 90: 29-58.

ALMEIDA FFM. 1977. 0 Cráton São Francisco. RBG, 7(4): 349-364.

ARAÚJO JGM. 2001. Influência das zonas de cisalhamento de São Vicente e Tapera na mineralização aurífera do Quadrilátero Ferrífero, Minas Gerais. Instituto de Geociências. Universidade de Brasília. Brasília. Dissertação de mestrado. $100 p$

BARBOSA ALM. 1968. Contribuições recentes à geologia do Quadrilátero Ferrífero. IGC-UFMG (1985), 44p.
CARNEIRO MA. 1992. O Complexo Metamórfico Bonfim Setentrional (Quadrilátero Ferrífero, Minas Gerais): Litoestratigrafia e Evolução Geológica de um Segmento de Crosta Continental do Arqueano. São Paulo, 233p. (Tese de Doutoramento, Instituto de Geociências da Universidade de São Paulo).

CARNEIRO MA, NOCE CM \& TEIXEIRA W. 1995. Evolução policíclica do Quadrilátero Ferrífero: uma análise fundamentada no conhecimento atual da geocronologia U-Pb e geoquímica isotópica Sm-Nd. Revista da Escola de Minas, 48 (4): 264-273.

CHEMALE JR F, ROSIÈRE CA \& ENDO I. 1991. Evolução tectônica do Quadrilátero Ferrífero, Minas Gerais - Um modelo (Tectonic Evolution of the Quadrilátero Ferrífero, Minas Gerais. A Model). Pesquisas, 18: 104-127.

CHEMALE JR F, ROSIÈRE CA \& ENDO I. 1994. Tectonic Evolution of the Quadrilátero Ferrífero, MG, Brazil. Precambrian Research, 65: 25-54.

CORDANI UG, KAWASHITA K, MUELLER G, QUADE H, REIMER V \& ROESER HP. 1980. Interpretação tectônica e petrológica de dados geocronológicos do embasamento do bordo sudeste do Quadrilátero Ferrífero, Minas Gerais. Anais da Academia Brasileira de Ciências, Rio de Janeiro, 52: 785-799.

CORDANI UG, TEIXEIRA W, SIGA JR 0. 1989. Geocronologia do Quadrilátero Ferrífero. In: XXI Semana de Estudos de Ouro Preto, SICEG, Ouro Preto, Bol. 21: 27-44.

CROCCO-RODRIGUES FA, RIBEIRO-RODRIGUES LC \& ROSIERE CA. 1991. Análise crítica sobre a controvérsia do Grupo Tamanduá, Quadrilátero Ferrífero. In: $6^{\circ}$ Simpósio de Geologia de Minas Gerais/ XXX 
Semana de Estudos de Ouro Preto, SICEG, Ouro Preto. Anais ..., Revista da Escola de Minas, 45(1/2): 47-48.

DORR II JVN. 1969. Physiographic, Stratigraphic, and Structural Development of the Quadrilátero Ferrífero, Minas Gerais. U.S.G.S. Paper, 641-A: 1-110.

FREITAS ME, CROCCO-RODRIGUES FA \& ROSIÈRE CA. 1991. A correlação do Quartzito Cambotas com a Seqüência Espinhaço apoiada por mapeamento geológico em escala 1:10.000. In: 6 Simpósio de Geologia de Minas Gerais / XXX Semana de Estudos de Ouro Preto, SICEG. Anais..., Revista da Escola de Minas, 45(1/2): 51-53.

FUCK RF. 2001. Reprocessamento dos Dados Aerogeofísicos do Projeto Rio das Velhas. Relatório bolsa RHAE. CNPq.

HERTZ N. 1978. Metamorphic rocks of the Quadrilátero Ferrífero, Minas Gerais, Brazil. U.S.G.S. Professional Paper, 641-C: 1-81.

HILDENBRAND JD \& PEREZ DA GAMA MF. 1993. Levantamento Aéreo Magnetométrico, Gamaespectrométrico e Eletromagnético. Aquisição, Processamento e Interpretação dos Dados. Projeto Rio das Velhas. Relatório Final. Prospec S/A (inédito), 1: 47.

HOEFS J, MULLER G \& SCHUSTER AK. 1982. Polymetamorphic relations in iron ores from the Iron Quadrangle, Brazil: the correlation of oxygen isotope variations with deformation history. Contributions to Mineralogy and Petrology, 79: 241-251.

JORDT-EVANGELISTA H, ALKMIM FF \& MARSHAK S. 1991. Metamorfismo progressivo e a ocorrência dos três polimorfos de $\mathrm{Al}_{2} \mathrm{O}_{3} \mathrm{SiO}_{5}$ (cianita, andaluzita e silimanita) na Formação Sabará em Ibirité, Quadrilátero Ferrífero, MG. In: $6^{\circ}$ Simpósio de Geologia de Minas Gerais/ XXX Semana de Estudos de Ouro Preto, SICEG. Anais ..., Revista da Escola de Minas, 45(1 e 2): 157-160.

LADEIRA EA. 1980. Metallogenesis of Gold at the Morro Velho Mine, and in Nova Lima District, Quadrilátero Ferrífero, Minas Gerais, Brazil. Unpubl. PhD thesis, University of Western Ontario, London, 272 pp.

LADEIRA EA \& VIVEIROS JFM. 1984. Hipótese sobre a estruturação do Quadrilátero Ferrífero com base em dados disponíveis. Boletim da Sociedade Brasileira de Geologia-Núcleo Minas Gerais, 4: 1-14.

MACHADO N \& CARNEIRO MA. 1992. U-Pb evidence of late Archaean tectono-thermal activity in the southern São Francisco shield, Brazil. Canadian Journal of Earth Sciences, 29(11): 2341-2346.

MACHADO N, NOCE CM, BELO DE OLIVEIRA OA \& LADEIRA EA. 1989. Evolução geológica do Quadrilátero Ferrífero Arqueano e Proterozóico Inferior, com base em geocronologia U/Pb. In: $5^{\circ}$ Simpósio de Geologia do Núcleo Minas Gerais - $1^{\circ}$ Simpósio de Geologia do Núcleo.

MARSHAK S \& ALKMIM FF. 1989. Proterozoic Extension/Contraction Tectonics of the São Francisco Craton and Adjacent Regions, Minas Gerais, Brazil: A Kinematic Model Relating Quadrilátero Ferrífero, São Francisco Basin and Cordilheira do Espinhaço. Tectonics, 8 (3): 555-571.
NOCE CM. 1995. Geocronologia dos Eventos Magmáticos, Sedimentares e Metamórficos do Quadrilátero Ferrífero, Minas Gerais. São Paulo. 128p. Instituto de Geociências da Universidade de São Paulo. Tese de Doutorado.

NOCE CM, PINHEIRO SO, LADEIRA EA, FRANCA CR \& KATTAH S. 1992. A seqüência vulcanossedimentar do Grupo Nova Lima na região de Piedade do Paraopeba, oeste do Quadrilátero Ferrífero, Minas Gerais. Revista Brasileira de Geociências, 22(2): 175-183.

PALACKY GJ. 1991. Resistivity characteristics of geologic targets. In: NABIGHIAN MN (Ed.). Electromagnetic Methods in Applied Geophysics. Society of Exploration Geophysicists, Tulsa, Oklahoma, 1: 53-129.

PINTO PC. 1996. Explanatory notes / Rio das Velhas project. Rel. téc. DNPM - SUREG/BH.

PINTO PC \& SILVA LC. 1996. Contrasting Tectono-Stratigraphic Domains in the Rio das Velhas Greenstone Belt (RVGB), MG, Brazil. In: SBG, Symposium Archaean Terranes of the South American Platform. Brasilia, Anais, 23-25.

REID AB, ALLSOP JM, GRANSER H, MILLETT AJ \& SOMERTON IW. 1990. Magnetic interpretation in three dimensions using Euler deconvolution. 58th Annual International Meeting. Society of Exploration Geophysicists.

REIS LA, MARTINS-NETO MA, GOMES NS, ENDO I \& JORDT-EVANGELISTA H. 2002. A bacia de antepaís paleoproterozóica Sabará, Quadrilátero Ferrífero, Minas Gerais. Revista Brasileira de Geologia, 32(1): 27-42.

ROMANO AW. 1989. Evolution tectonique de la région NW du Quadrilatère Ferrifère - Minas Gerais, Brésil. Nancy, 259p. (Thèse Docteur, Université de Nancy I).

SCHRANK A \& SILVA MG. 1993. Os greenstone belts do Cráton do São Francisco, Brasil. In: DOMINGUEZ JML \& MISI A (Ed.). 0 Cráton do São Francisco. Salvador, SBG/SGM/CNPq, pp. 85-118.

SCHORSCHER HD. 1978. Komatiitos na estrutura greenstone belt Série Rio das Velhas. Quadrilátero Ferrífero, Minas Gerais, Brasil. XXX Congr. Bras. Geol., Anais... Recife, Bol. Esp. 1: 292-293.

SILVA AM. 1999. Geophysical and Geological Data Integration Using a New Statistical Approach for Mineral Target Selection Applied to the Rio das Velhas Greenstone Belt, Quadrilátero Ferrífero. Inst. de Geociências, Universidade de Brasília, Brasília, Tese de Doutoramento.

SILVA AM, CHEMALE JR F \& KUYUMJIAN RM. 1995. 0 Ambiente tectônico dos diques máficos do Quadrilátero Ferrífero e Espinhaço Meridional e suas implicações para a evolução do Cráton São Francisco. In: Simpósio Nacional de Estudos Tectônicos, 5, Gramado. SBG-CPGQUFRGS, 1996. Boletim de Resumos Expandidos..., p. 209-210.

TEIXEIRA W. 1985. A Evolução Geotectônica da Porção Meridional do Cráton São Francisco, com Base em Interpretações Geocronológicas. 
São Paulo. 207p. (Tese de Doutorado, Instituto de Geociências da Universidade de São Paulo).

TEIXEIRA W, CARNEIRO MA, NOCE CM, MACHADO N, SATO K \& TAYLOR PN. 1996. Pb, Sr and Nd isotope constrains on the Archaean evolution of gneissic-granitoid complexes in São Francisco Craton, Brazil. Precambrian Research, 78: 151-164.

ZONGE KL \& HUGHES LJ. 1991. Controlled Source Audio-Frequency Magnetotellurics. In: NABIGHIAN MN (Ed.). Electromagnetic Methods in Applied Geophysics. Society of Exploration Geophysicists, Tulsa, Oklahoma, 2: 713-810.

ZUCCHETTI M, BALTAZAR OF \& RAPOSO F0. 1996. Estratigrafia. Projeto Rio das Velhas. Mapa Geológico Integrado. Escala: 1:100000. Texto Explicativo. Programa de Estudos Mineiros. Convênio DNPM-CPRM. DNPM-Secretaria de Minas e Energia-Ministério de Minas e Energia. Belo Horizonte, 1996, p. 13-42.

\section{NOTAS SOBRE OS AUTORES}

Alexandre de Amorim Teixeira. Geólogo pela Universidade de Brasília - UnB (2000) e Mestre (2003) em processamento de dados em geologia e análise ambiental pela Universidade de Brasília. Atualmente, é especialista em geoprocessamento pela Agência Nacional de Águas - ANA.

Adalene Moreira Silva. Engenheira Geóloga (1989) graduada pela Universidade Federal de Ouro Preto, Mestre (1992) e Doutora em Geologia (1999) pela Universidade de Brasília. Profissionalmente, atuou como pesquisadora do Serviço Geológico Americano (1997-1999), Professora Visitante da Universidade de Brasília (2000-2002), Pesquisadora (05/2002-04/2003) e Professora do Instituto de Geociências da UNICAMP (04/2003-10/2005). Atualmente é Professora do Instituto de Geociências da Universidade de Brasília e vem pesquisando sobre novas técnicas de processamento, interpretação e integração de dados aplicados a exploração mineral, hidrogeologia e ambiente.

Augusto César Bittencourt Pires. Geólogo e geofísico, formado em 1968 pela UFRJ. Ph.D. em Geofísica pela Colorado School of Mines em 1975 e com PósDoutorado em Geofísica pela mesma instituição. Foi responsável pelo departamento de Geofísica da ENCAL; Chefe do Departamento de Geofísica do Observatório Nacional; Chefe do Centro de Geofísica Aplicada do DNPM. No CNPq exerceu funções de Supervisor a Diretor de Programas. Foi Diretor de Programas da CAPES e Coordenador de Políticas e Planos do MCT. Foi Consultor Legislativo do Senado. É Professor Titular, Coordenador do Laboratório de Geofísica Aplicada da UnB e consultor sênior da HGeo/ InterGeo.

Roberto Alexandre Vitória de Moraes. Geólogo (1968) pela UFPe; Ph.D. em Geofísica (1997) Colorado School of Mines, Golden, C0, EUA. Geofísico do DNPM, Rio de Janeiro-RJ; geólogo/geofísico da DOCEGEO, Belo Horizonte-MG; geofísico-chefe da PROSPEC S/A, Rio de Janeiro-RJ; geofísico-chefe do SEMEPO da Paulipetro, São Paulo-SP; geofísico-chefe da Petromisa, Rio de Janeiro-RJ; geofísico sênior da Petrobras, Rio de Janeiro-RJ, pesquisador sênior do IPT, São Paulo-SP e Professor Adjunto do IG da UnB. Especialista nos métodos magnético, gravimétrico, elétrico, eletromagnético (aéreos e terrestres), gamaespectrométrico e em métodos numéricos para modelagem e inversão em Geofísica. Diretor Científico da HGeo e da InterGeo.

Carlos Roberto de Souza Filho. Engenheiro Geólogo (Universidade Federal de Ouro Preto, 1988), Mestre em Metalogênese (UNICAMP, 1991), PhD (Open University, Inglaterra, 1995, Jovem-Pesquisador (FAPESP-UNICAMP, 1995-1997), Professor-Doutor (UNICAMP, 1997-2002). Desde 2002, é Professor Livre Docente do Departamento de Geologia e Recursos Naturais do Instituto de Geociências da UNICAMP. Atualmente é Coordenador do Programa de Pós-graduação de Geociências e líder do Grupo de Geotecnologias do IG. Pesquisador Nível 1 do CNPq, é responsável pelos laboratórios de pesquisa em Fs-LA-ICP-MS (IsoGeo), Espectroscopia de Reflectância (LER) e Processamento de Informações Georreferenciadas (LAPIG). É pesquisador da NASA nos programas ASTER e Mars-Earth Analogs, Editor-Associado das Revistas Computers \& Geosciences e Mathematical Geology. 